Short Note

\title{
Spatial mapping of forest soil organic carbon in Nepal's Terai district
}

\author{
S. Khanal ${ }^{1 *}$, S. Paudel ${ }^{1}$ and S. Chaudhary ${ }^{1}$
}

$\mathrm{P}$ eriodic forest resource assessment is one of the key activities for the forestry sector. It is essential to get the updated information for supporting policy formulation and management decisions. Further, in the current context of climate change, international initiatives such as REDD+ requires periodic reporting of different forest carbon pools using standard set of scientifically valid methods. The carbon in forests is stored in different carbon pools both above as well as below ground. Considering the significance of soil carbon to the total carbon pool, recent forest resource assessment of Nepal has included comprehensive soil carbon sampling so as to provide estimates of this carbon pool (DFRS, 2015a). Often forest resource assessments including soil sampling are also conducted on smaller scale sub-national areas such as districts. The findings from such assessments contribute to understanding of soil carbon and its contribution to total carbon pools.

Research gaps exist in different aspects of forest soil organic carbon (SOC) such as management impact on soil carbon and factors driving its spatial variability. Understandings on such concepts are very imperative for better forest management prescriptions so as to enable more carbon sequestration in forests. With the objective to identify better methods of resource assessment in district level, DFRS had implemented comprehensive forest resource assessment in selected Terai district of Nepal. The forest type mapping results has already been published (Chaudhary et al., 2015). This short note presents the spatial mapping forest soil organic carbon (SOC).

The study was conducted on Kapilvastu district in Terai region of Central Nepal (Fig. 1). Forest, Other wooded land and shrub land cover 59.02 thousand hectares, 1.78 thousand hectares and

0.17 thousand hectares respectively (DFRS, 2015a). Kapilvastu district is situated in Lumbini Zone of Western development region of Nepal. It spreads ranging from 93 to $1491 \mathrm{~m}$ above sea level. The forest area mask was obtained from recent forest cover mapping done (DFRS, $2015 b$ ). On the forested area the sampling grid was generated at the spacing of $500 \mathrm{~m}$. Out of the 2451 regular plots, random sample of 184 were taken for field measurement (Fig. 1).

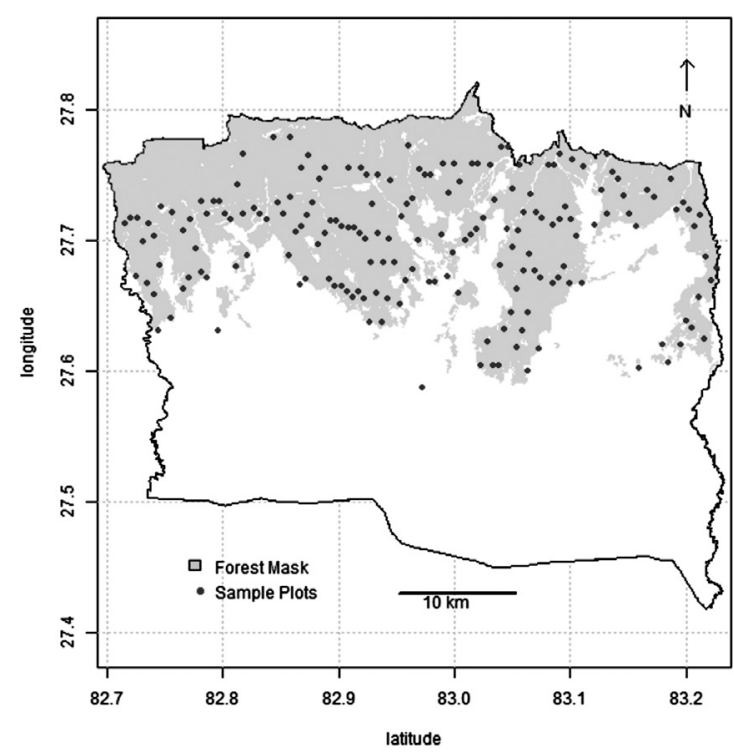

Fig. 1: Map showing the Kapilbastu district, the forested area and the sample plots measured over the forested area of the district.

Four soil pits were dug in each cardinal direction at the distance of 21 meters from the plot center. The $100 \mathrm{~mm}$ long soil corer with a lower diameter of $37 \mathrm{~mm}$ (at its cutting edge) and an upper diameter of $40 \mathrm{~mm}$ was used to collect separate soil samples from three layers i.e., $0-10 \mathrm{~cm}$, $10-20 \mathrm{~cm}$ and $20-30 \mathrm{~cm}$ depth. The fresh mass of composite sample was determined onsite. The relative volume occupied by stones in the soil was estimated occularly by observing the soil pitwalls by using the FAO Guidelines (FAO, 2006).

Department of Forest Research and Survey. *E-mail: khanalshiva1@gmail.com 
The composite soil samples were first air-dried and later oven-dried to constant weight. The oven-dried sample was immediately weighed for total bulk density and then sieved through a $2 \mathrm{~mm}$ sieve and soil fine fraction (FF) obtained. The volume of coarse fraction (not passing the sieve) was determined from water replacement method. The bulk density of the soil fine fraction was then calculated by eliminating the volume of the coarse fraction. The bulk-density of the fine soil fraction for each soil layer was used to calculate the organic carbon stock in each of the $10 \mathrm{~cm}$ soil layers. The partial wet combustion method (Walkley and Black, 1934) was used to estimate SOC with a correction factor of 1.3.

The soil organic carbon (SOC) stock was calculated by multiplying the dry soil bulk density $\left(\mathrm{g} / \mathrm{cm}^{3}\right)$ by the proportion of OC as analyzed in the fine fraction (FF) of soil. The final SOC FF, adj value was obtained after adjusting the laboratory results with a consideration of the proportion (Stone \%) of stoniness determined in the field. The soil sampling and subsequent SOC estimation approach was adopted from the national forest resource assessment (DFRS, 2015).

For spatial prediction of SOC, covariates were prepared using Landsat 8 imageries and terrain parameters. Composite of median reflectance from Landsat- 8 images (using total 81 scenes from year 2015 to 2016) was generated using Earth Engine platform (Google Earth Engine Team, 2015). The study area was in the overlap area of Landsat path-row (142-41 and 143-41) and each had 40 and 41 scenes respectively. Five bands (blue, green, red, nir and swir) were selected. $30 \mathrm{~m}$ spatial resolution SRTM 1 Arc-Second Global elevation data for the study area were obtained from EarthExplorer (U.S. Geological Survey (USGS), Earth Resources Observation and Science (EROS) Center). Slope and aspect were derived from the dem using 9 parameter and 2nd order polygon method available in QGIS. Topograhic wetness index (TWI) layer was also derived based on standard method in Saga 2.1.2 (Conrad et al. 2015).

Random Forest (RF) technique was used to model relationships between field measured SOC and environmental covariates. This technique has become increasingly popular in ecology and has also been applied in estimation of SOC (Yang et al. 2016). The model fitting and spatial prediction was done in $\mathrm{R}$ using random Forest (Liaw and Wiener, 2002) and Raster package (Hijmans, 2006). The spatial prediction of SOC was done separately for three depths: $0-10 \mathrm{~cm}, 10-20 \mathrm{~cm}$ and $20-30 \mathrm{~cm}$. The fourth output layer was total SOC in all three layers combined. For evaluation of prediction model, $\mathrm{k}$-fold cross validation was done. All the analysis in this paper were done using R software.

The average SOC based on 184 sample was calculated by depth class (Table 1). The SOC varied with the sampling depth having lower SOC stock on deeper soils. Last national forest resource assessment estimated $33.66 \mathrm{t} / \mathrm{ha}$ and $31.44 \mathrm{t} / \mathrm{ha}$ SOC for Terai and Churia (DFRS, 2015a). This district level estimate which combines plots from both Terai and Churia is 38.01 t/ha however unlike this study, the national scale assessment accounted for litter and woody debris as well.

Table 1: Summary statistics for results across all 184 plots measured

\begin{tabular}{ccrrrr}
\hline $\begin{array}{c}\text { Depth } \\
\text { (cm) }\end{array}$ & $\begin{array}{c}\text { No of } \\
\text { Obs }\end{array}$ & $\begin{array}{c}\text { Average } \\
\text { (T/ha) }\end{array}$ & sd & se & $\begin{array}{c}\text { 95\% } \\
\text { CI }\end{array}$ \\
\hline $0-10$ & 184 & 17.75 & 10.07 & 0.74 & 1.48 \\
$10-20$ & 184 & 11.04 & 6.75 & 0.50 & 0.99 \\
$20-30$ & 184 & 9.21 & 5.26 & 0.39 & 0.77 \\
\hline
\end{tabular}

Elevation was observed as an important covariate for SOC content in all depth classes. Similarly, latitude, Landsat 4 band (NIR) and Landsat 1 and 2 were also important ones (Fig. 2).

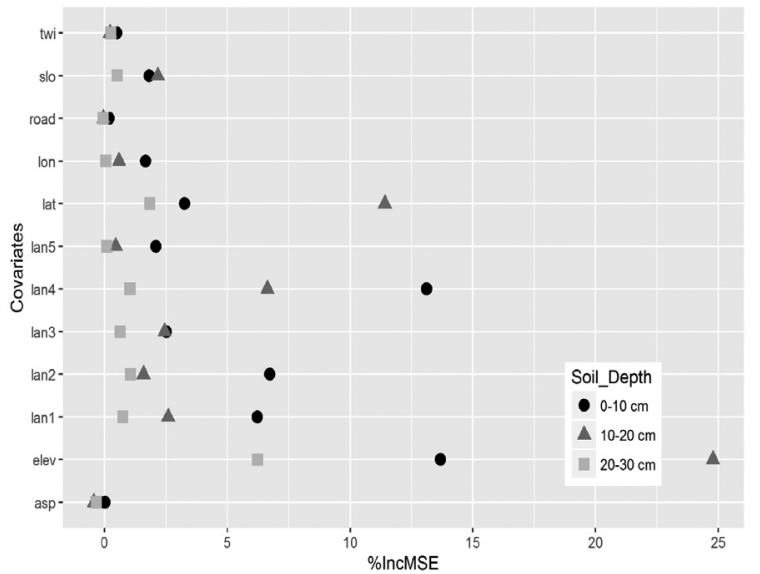

Fig. 2: Covariate importance from RF. twi = topographical wetness index, elev = elevation, slo $=$ slope, road $=$ distance from road, lon $=$ longitude, lat= latitude, lan 1 to lan $5=$ Landsat reflectance from band $1-5$, asp $=$ aspect 
Yang et al. 2016 have reported that mean annual precipitation, NDVI, mean annual temperature, Landsat TM Band 5 are important predictors to explain SOC. Given the relatively small area and lack of high resolution climatic observation, the climatic predictors were not used in the models.

The fitted RF model was applied on the environmental covariates for spatial prediction of SOC (Fig. 3). In predicted SOC map the areas in the North had higher SOC for all sample depth layers. This variation could be due to the fact that those sites are in the Churia Hills compared to flat plains in areas in the south. The flat areas have higher disturbance due to human activities such as grazing and litter collection compared to Churia, which has typically difficult terrain. However, further study is required in order to understand the variation in spatial distribution of SOC. Performance of the RF models were assessed using $\mathrm{k}$-fold cross validation for the RF model applied to each of the SOC depth layers. 10 fold cross validation gave the RMSE of 7.1, $4.5,3.9$ and 12.3 for layers $0-10 \mathrm{~cm}, 10-20 \mathrm{~cm}$, $20-30 \mathrm{~cm}$ and $0-30 \mathrm{~cm}$ respectively. The models using the given covariates had R-squared values around 0.2 for each layers.

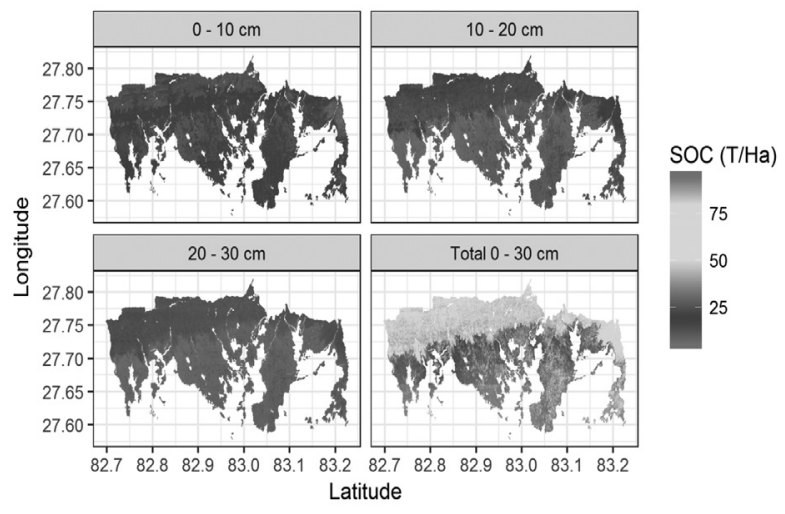

Fig. 3: Spatial distribution of SOC stock. The figure was produced using ggplot2 package (Wickham, 2009).

\section{Acknowledgements}

The study was funded by Government of Nepal under Forest Research and Survey Project implemented by Department of Forest Research and Survey. The authors would like to acknowledge all the forest inventory crew members who took part on this field data collection mission.

\section{References}

Chaudhary A. K., Acharya A. K. and Khanal S. 2016. Forest type mapping using objectbased classification method in Kapilvastu district, Nepal. Banko Janakari 26 (1): $38-44$.

Conrad, O., Bechtel, B., Bock, M., Dietrich, H., Fischer, E., Gerlitz, L., Wehberg, J., Wichmann, V. \& Böhner, J. 2015. System for automated geoscientific analyses (SAGA) v. 2.1. 4. Geoscientific Model Development 8 (7): 1991-2007.

DFRS, 2015a. State of Nepal's Forests. Forest Resource Assessment (FRA) Nepal, Department of Forest Research and Survey (DFRS). Kathmandu, Nepal.

DFRS, 2015b. District Forest Cover Maps of Nepal. Forest Resource Assessment (FRA) Nepal, Department of Forest Research and Survey (DFRS), Kathmandu, Nepal.

Google Earth Engine Team, 2015. Google Earth Engine: A Planetary-Scale Geospatial Analysis Platform. https://earthengine. google.com

FAO, 2006. Guidelines for Soil Description (4th edition). Food and Agriculture Organization of the United Nations (FAO), Rome, Italy.

Hijmans Robert J. 2016. raster: Geographic Data Analysis and Modeling. $\mathrm{R}$ package version 2.5-8. https://CRAN.R-project.org/ package $=$ raster.

Liaw A. and Wiener M. 2002. Classification and Regression by randomForest. $R$ News 2 (3): $18-22$.

USGS, https://lta.cr.usgs.gov/SRTM1Arc

Walkey, A. and Black, I. A. 1934. An examination of the digitized method for determining soil organic matters, and a proposed modification of the chromic acid titration method. Soil Science 37: 29-38.

Wickham H 2009. ggplot2: Elegant Graphics for Data Analysis. Springer-Verlag, New York, USA.

Yang, R. M., Zhang, G. L., Yang, F., Zhi, J. J., Yang, F., Liu, F., \& Li, D. C. 2016. Precise Estimation of Soil Organic Carbon Stocks in the Northeast Tibetan Plateau. Scientific reports, 6 . 